\title{
Possibilities of the biological method of cotton plant protection
}

\author{
M.N. Yusupova ${ }^{1}$, S.T.Hodzhaev ${ }^{2}$ and K.S.Mamatov ${ }^{2}$ \\ ${ }^{1}$ Andizhan Agricultural Institute, \\ ${ }^{2}$ The Uzbek Scientific Research Institute of Plants Protection \\ Corresponding author: M.N. Yusupova, Ph. D., Docent, Research Fields: Plant Protection. \\ Email: maxpuza-70@mail.ru
}

\begin{abstract}
In Uzbekistan biological protection of cotton from cotton borers (CB) and other pests is spent in the system of the integrated protection of plants (ISPP). For this purpose on republic regions the network of a laboratory-factory lifetime of bio agents is adjusted: trichogramma (Tr. pintoi, Tr. evanescens) - against eggs of borers, bracona (Bracon hebetor) - against caterpillars of the pests. Simultaneously turn out a polytrophic lacewing (Chrysopa carnea) - for enrichment of agro biocenosis. For establishment of value of biomaterials quality in aggression and received efficiency in 2007-2008 the field experiments have been made. For the standard the populations from specialized bio laboratory of Tashkent state agrarian university are taken. Populations from local bio laboratories, on quality differing from the standard were compared. Entonophages were used on signals of pheromone traps for $\mathrm{CB}$. The account of the pests was spent by the technique established in republic. As a result of experiences the following has been established: biological efficiency of 3 multiple outlets of trichogramma on $1 \mathrm{gr} / \mathrm{ha}$ does not exceed 44,3\% (13,2-21,2 \% of not qualitative and, $24,3-44,3 \%$-of standard trichogramma). The same results has shown also the colonization of bracon (2-multiple outlet of a parasite in parities 1:10-15 caterpillars against each generation of borers) $-17,5 \%-34,2 \%$ and $21,4-47,2 \%$ accordingly. The conclusion on necessity of maintenance of quality of a biomaterial at high demanded level has been made.
\end{abstract}

Keywords: biological method of plant protection trichogramma, bracon, cotton columbine borer, entomophages, lacewing, effectiveness, integrated system of plants protection (ISPP), predator, victim.

\section{INTRODUCTION}

As it is known, generally recognized and widely used in many countries of the world including Uzbekistan, the so-called integrated system of plants protection (ISPP) provides carrying out of such tactics of plants protection at which number (density) of the pest(s) restrains at economic-harmless level, practically reducing their number to criterion of economic thresholds of harmful number $(\mathrm{ETH})$. Control levers of such system are all possible methods, to some extent capable to lower the number of harmful organisms (organizational-economic, agro technical, mechanical, selective, genetic, biological, chemical, etc.) to economic imperceptible level. Hence, a biological method of protection of plants calculated on efficiency of not only artificially flooded bio agents (trichogramma, bracon, lacewing, etc.), but also on natural self-control of arthropods animals, is being one of the elements of ISPP. And as value of this method is great, the method of biological protection of plants is one of the basic and solving in ISPP [1-4]. Nevertheless, it is impossible to forget, that it is only one of protection methods of ISPP elements and that it is not all-powerful [6]. There are results of numerous experiences which say that in natural conditions the entomophages seldom destroy their victim on $100 \%$. At least for this purpose coincidence of two factors is necessary: high density and vital indicators of one or several target entomophages and adversity of climatic conditions for successful development of a harmful organism.

\section{MATERIALS AND METHODS}

Work was spent in the Andizhan area of Uzbekistan. In work methods of laboratory raring and application of entomophages $[7,8]$ have been used. Accounts of insects were spent according to methodical instructions [9].

Definition of optimum terms of trichogrammas outlets was made on signals of pheromone traps given by 
institute of bio organic chemistry of Academy of sciences of the Republic of Uzbekistan [10].

\section{RESULTS AND DISCUSSION}

In the Andizhan area, after a long depressive for development of cotton columbine borer (Helicoverpa armigera Hb.) years, in 2007 and 2008 a mass development of this pest at flash level was observed. In 2007 in economies of Balikchin area the series of experiences for efficiency studying of trichogramma (Trichogramma pintoi) and bracon (Bracon hebetor), reared in local bio laboratories, and also brought from bio factory of Tashkent state agrarian university
(TSAU) have been spent. In the table schemes of experience variants are resulted: efficiency of trichogramma (on indexes of eggs infection rate), and also of bracon on infection of cotton borers caterpillars.

From the received results follows, that low results were shown at use of laboratory reared bio agents. At natural fertility (sterility) of eggs at level of $35-41 \%$ and natural infection of eggs by trichogramma $-2,1$ $3,7 \%$ (control-I), local population of a parasite has shown only efficiency at level of $13,2-21,2 \%$, and made in TSAU was better, but also that only made $24,3-44,3 \%$.

Dependence of effectiveness of trichogramma and bracon versus cotton borers on their quality Production experience, the Andizhan area, 22.07-09.08.2007

\begin{tabular}{|c|c|c|c|c|c|c|c|}
\hline \multirow{3}{*}{ № } & \multirow{3}{*}{ Experience variants } & \multicolumn{6}{|c|}{ Infection \%\% on days: } \\
\hline & & \multicolumn{3}{|c|}{ Eggs } & \multicolumn{3}{|c|}{ Caterpillars } \\
\hline & & 3 & 6 & 9 & 3 & 6 & 9 \\
\hline 1. & $\begin{array}{l}\text { Trichogramma (local population) - } 3 \\
\text { multiple outlet }\end{array}$ & 13,2 & 21,2 & 16,5 & - & - & - \\
\hline 2. & $\begin{array}{l}\text { Trichogramma (TSAU) - } 3 \text { multiple } \\
\text { outlet }\end{array}$ & 24,3 & 37,2 & 44,3 & - & - & - \\
\hline 3. & $\begin{array}{l}\text { Control-I (Natural infection of eggs } \\
\text { by trichogramma) }\end{array}$ & 2,1 & 3,3 & 3,7 & - & - & - \\
\hline 4. & Control-II (Natural sterility of eggs) & 41,5 & 36,1 & 35,0 & - & - & - \\
\hline 5. & $\begin{array}{l}\text { Bracon (local population)-2-multiple } \\
\text { outlet in 1:15-20. The general norm } \\
\text { of outlets } 5000 \text { ex/ha }\end{array}$ & - & - & - & 17,5 & 34,2 & 30,5 \\
\hline 6. & $\begin{array}{l}\text { Bracon (TSAU)- 2-multiple outlet in } \\
1: 15-20 \text {. The general norm of } \\
\text { outlets } 5000 \mathrm{ex} / \mathrm{ha}\end{array}$ & - & - & - & 21,4 & 45,4 & 47,2 \\
\hline 7. & The control (naturally) & - & - & - & 3,4 & 11,2 & 7,3 \\
\hline
\end{tabular}

The number of cotton borers' caterpillars was so high that it was necessary to let out unusually considerable quantity of bracon -5000 ex/ha. The results also have shown, that local populations of this parasite are less effective - 17,5-34,2 \% within 9 days after 2 let outs, and from TSAU, accordingly $21,4-47,2 \%$.

Approximately the same results have been received at another our experience spent in 2006 in the conditions of the Andizhan area. Thus, it is possible to conclude, that carrying out of biological control against cotton borers with the help of trichogramma and bracon are justified on sites with moderate number of the pests in limits till 20-25 eggs and caterpillars on 100 plants on the average. In cases of mass reproduction of cotton borers it is expediently to use insecticide protection. Thus, the efficiency of a method will depend again on correctness of selection of the scientifically-proved terms of processing carried out.

Namely, it will be effective in overwhelming cases only when it coincides with the moment of mass oviposition and pests' caterpillars' birth. These terms can be defined only by frequent qualified accounts of observers - keepers with involvement of the control of pheromone method. 
Special interest in a biological method of plants protection represents raring and application of predatory lacewings (fam. Chrysopidae). As it is known in agro biocenosis of the Republic are living over 10 kinds of chrysopas [5]. Among kinds dominate: ordinary lacewings- Chrysopa carnea Steph., seven-dot - Ch. septempunctata Wesm. And beautiful one - Ch. formosa $\mathrm{Br}$.

Lacewing is the predator-polyphage destroying representatives of many kinds of arthropods animals in biotops with crops. To it are peculiar a number of the merits favourably distinguishing it from others entomophages. But at the same time, there are also the lacks constraining its wider use, than it now is. So, that is its nature - an expressed cannibalism in a stage of larvae development. It essentially brakes the process of laboratory raring of a kind. And the mechanized process of reproduction based on individual development of individuals with use of ANM (artificial nutritious means) -is expensive and economically unprofitable [5].

In Uzbekistan a technique of laboratory cultivation of lacewings on eggs of cytotroge and outlet of a predator on fields in a phase of eggs and imago is adjusted [8]. How much effective and profitable this technique is? Considering results of numerous experiments which have shown, that lacewing is effective at outlet of its larvae in parities to victims $1: 10-15$, it is possible to ascertain, that one lacewing is not enough to reach efficiency. First because it is impossible to get such necessary quantity of larvae in laboratories; secondly, the eggs settled on fields become easy extraction of ants, and also of secondary parasites (accounts have shown, that in June on cotton fields of the Fergana area it is possible to count about 350 ants on $\mathrm{m}^{2}$ ). Thirdly, it can manage very expensively in financial expression.

There are two ways of practical use of laboratory reared lacewing. The first - early (spring) enrichment of boundaries, roadsides, alfalfa fields and early crops and the second - local use of the big norms of entomophages let out on the early-spring covered vegetable sowings and in hothouses with advantage of outlet of larvae of a predator in parities 1:10-15 to victims, and also imago - for enrichment of concrete agro biocenosis.

In any case, use of a biological method of cotton plant protection from cotton borer and other kinds of it in the conditions of Uzbekistan is economically and ecologically demanded, for only it promoted to reduce frequency rate of chemical processings from 10-12 (till 1980) to 0,7-1,3 (2008-2009).

\section{CONCLUSIONS:}

In Uzbekistan the biological method of cotton protection from cotton borers (Helicoverpa armigera $\mathrm{Hb}$ ) and other kinds of borers is widely used. In these purposes are used: against eggs - trichogramma ( $T r$. pintoi, Tr. evanesens), caterpillars - bracon (Br. hebetor). Stations enrich by lacewing (Chrysopidae). By experiences it is established, that biological effectiveness of trichogramma against borers in strong degree depends on their quality and can make from $13,2-21,2 \%$ to $24,3-44,3 \%$, and bracon - from $17,5-34,2 \%$ to $21,4-47,2 \%$.

\section{REFERENCES}

1. Viktorov G. A. Principles and methods of the integrated pest control of agricultural crops//Biol. means of plants protection. - M: Kolos, 1974. - p. 11-20.

2. Narzikulov M. N, Umarov Sh.A. Not to mow, as a plait, and to strike, as a sword//Protection of plants. 1980. - №1. - p. 17-19.

3. Kan A.A., Кім Ch.N. Integrated cotton plant protection against pests. - Tashkent: Mehnat, 1988. - p.76.

4. Uspensky F.M., and others. System of integrated pest control of cotton plant. - Tashkent: Fan, 1969. p. $89-100$.

5. Radzilovskaya M.A. Lacewing against a plants aphid on a cotton//Protection of plants. - 1980. - №10. - p. 26.

6. Hodzhaev S.T., Jusupova M. N, Kuryasov Sh.,Sattarov N. Perspectives of biological protection of a cotton from cotton borers// Works. - Tashkent: Talkin, 2008. - p. 44-49 (Uzb.).

7. Alimuhamedov S.N., Adashkevich B.P., Adylov Z.K., Khodjaev SH.T. Biological method of cotton plant protection - Tashkent: Mekhnat, 1990. - p. 172(Uzb.).

8. Mirzaeva H.R. Biological method of pest control of agricultural crops. - Tashkent: Matbuot, 1986. -p. 54.

9. Methodical instructions on test of pesticides. - Tashkent, 2004. -p. 103.

10. Methodical instructions on application of pheromones for definition of terms of trichogrammas outlet ( S.T.Hodzhaev, etc.) - Tashkent, 1984. - p.5. 